\title{
Estimación de un índice de calidad ambiental urbano, a partir de imágenes de satélite ${ }^{1}$
}

\author{
Luis Marino Santana Rodríguez ${ }^{2}$, Luis Alfonso Escobar Jaramillo ${ }^{3}$ \\ y Paolo Andrés Capote ${ }^{2}$
}

\begin{abstract}
RESUMEN
La implementación de políticas públicas, para resolver problemas ambientales urbanos, requiere de información que en la mayoría de las ciudades no existe. Por tanto, se propone un modelo para obtener un índice de calidad ambiental (ICA) urbano, a partir de imágenes satelitales. De una imagen Landsat ETM+ de Cali, Colombia se obtuvieron cinco indicadores ambientales: temperatura de superficie (TS), y los índices de vegetación normalizado (NDVI), de humedad en las hojas (LWCI), de suelos normalizado (NSI) y de vegetación ajustado al suelo (SAVI), con los que se estimó el ICA a nivel de barrio, usando análisis multivariado. Principalmente se obtuvo una alta correlación entre los indicadores; que los mayores valores del ICA ocurren en barrios con menor área construida y viceversa, y diferencias estadísticas significativas del ICA, según el uso del suelo. Los barrios fueron agrupados según el índice, destacando aquellos que demandan intervención prioritaria por las entidades de planificación.
\end{abstract}

Palabras clave: Sensores remotos, calidad ambiental, estudios urbanos, Cali.

\begin{abstract}
The implementation of public policies, to solve urban environmental problems, requires of information that in most of cities does not exist. Therefore, a model to obtain an urban environmental quality index (ICA), from satellite images, is proposed. From a Landsat ETM+ image of Cali-Colombia, five environmental indicators were obtained: temperature of surface (TS), normalized difference vegetation index (NDVI), leaf water content index (LWCI), normalized difference soil index (NSI) and soil adjust vegetation index (SAVI), from which the ICA was estimated, in a neighborhood level, using multivariate analysis. The results show that: 1) exists a high correlation among the indicators, 2) higher values of ICA take place in neighborhoods with smaller constructed area and vice versa, and 3) there's a significant statistical differences of ICA among pairs of land use. The neighborhoods were grouped according to the index, emphasizing those that demand high-priority intervention of planning institutions.
\end{abstract}

Key words: Remote sensing, environmental quality, urban studies, Cali.

1 Artículo recibido el 24 de agosto de 2009 y aceptado el 2 de octubre de 2009.

2 Departamento de Geografía, Universidad del VaIle (Colombia).E-mail: lusanta@univalle.edu.co; loanpote@univalle.edu.co
3 Escuela de Ingeniería de Recursos Naturales y del Ambiente, Universidad del Valle (Colombia). E-mail: lescobar@univalle.edu.co 
La mayoría de países de América Latina han experimentado, en las últimas cinco décadas, un proceso intenso de urbanización que ha modificado y complejizado el espacio urbano (Rodríguez y Villa, 1998), ocasionando impactos significativos sobre el medio, porque afecta: 1) los procesos de intercambio de energía entre la superficie de la tierra y la atmósfera, 2) el sistema hidrológico superficial y subsuperficial, 3) la calidad del aire y agua, y 4) las condiciones meso y microclimáticas (Wilson et al., 2003). Estos factores, que inciden en la calidad ambiental urbana y por tanto en el desarrollo social y económico de las ciudades, generalmente están asociados a la forma como los agentes sociales y sus actividades ocupan y utilizan el espacio, situación que crea nuevos retos para las autoridades y entidades de planificación urbana.

La calidad ambiental urbana se entiende como un conjunto complejo de factores humanos y ambientales interrelacionados (tipo, densidad y disposición de las construcciones, malla vial, densidad de población, presencia de áreas verdes, calidad del aire y del agua, islas de calor, entre otros) que inciden favorable o desafavorablemennte en la vida de los ciudadanos (Nichol \& Wong, 2005). La expresión y distribución de estos factores en las ciudades no son homogéneas y demandan, para su adecuada gestión y planificación, información que refleje las diferencias temáticas en el espacio y tiempo. Disponer de esta información no siempre es posible en las condiciones de los países en desarrollo, dado los altos costes de adquisición por medio de los métodos censales. En algunos casos, pueden existir datos e indicadores ambientales históricos, pero no siempre estos resultan adecuados, por cuanto han sido obtenidos mediante métodos diferentes o se encuentran a escalas inapropiadas. Combinar en una misma estructura analítica y espacial indicadores derivados de imágenes de sensores remotos y aquellos adquiridos adecuadamente mediante censos, permite construir sistemas de indicadores ambientales más eficientes y a más bajo coste para la toma de decisiones.

Los sensores remotos son una herramienta útil para entender y monitorear los procesos urbanos relacionados con el espacio físico, permitiendo construir bases de datos sobre el ambiente urbano (Weng, 2001) y a bajo coste. Adquieren información de forma continua en el espacio y con cierta frecuencia de tiempo, en distintas regiones del espectro y a diferentes escalas (Prihodko \& Goward, 1997), ampliando las posibilidades de utilización. De esta forma, el procesamiento digital de imágenes permite apoyar, de manera ágil y fiable, los procesos de toma de decisiones en la planificación y gestión ambiental urbana (Wilson et al., 2003), mediante la generación de indicadores ambientales.

En la revisión de la literatura especializada se encuentran múltiples trabajos sobre el ambiente urbano empleando indicadores temáticos derivados de imágenes de sensores remotos. La mayoría de ellos, usando distintos productos (NOAA-AVHRR, Landsat TM y ETM, MODIS, ASTER), están enfocados principalmente a: 1) la determinación y caracterización de clima e islas de calor urbano -UHI- (Yuan y Bauer, 2007; Tran et al., 2006; Santana, 2007; Chen et al., 2006; Pérez et al., 2003; Wong \& Yu, 2005; Rosenzweig et al., 2005), 2) clasificación de uso del suelo (Lu \& Weng, 2005; Lo \& Quattrochi, 2003; Dousset \& Gourmelon, 2003; Buyantuyev, 2007), 3) crecimiento urbano (Masek et al., 2000; Weng, 2001; Streutker, 2003; Martinuzzi et al., 2007; Jat et al., 2008), 4) densidad de población (Li \& Weng, 2005) y 5) evaluación de calidad y sostenibilidad ambientales (Romero y Vásquez, 2005; Fung \& Siu, 2000). Desde el punto de vista de las técnicas de transformación de las imágenes utilizadas, los mayores esfuerzos se han concentrado en índices o indicadores que muestran el estado y distribución de la vegetación y de las áreas construidas; siendo el índice de vegetación de diferencia normalizada (NDVI) y la temperatura de superficie (TS) las más usadas. El aumento de las áreas impermeables, producto de las construcciones presentes en las ciudades, y la disminución consecuente de las zonas con vegetación, altera la calidad ambiental, por cuanto modifica, entre otros (Romero y Vásquez, 2005): 1) el balance de energía, haciendo que aparezcan las UHI, 2) el ciclo hidrológico, con alteraciones en la velocidad de escurrimiento del agua y de los tiempos y volúmenes de recarga y descarga de los acuíferos subterráneos, 3) los hábitats naturales, y 4) el valor estético del paisaje. 
Por otro lado, considerando la información censal, los estudios de calidad ambiental urbana son escasos; por ejemplo, Escobar (2006) propuso un modelo de indicadores sintéticos de calidad ambiental para grandes zonas urbanas, construido a partir de información colectada a nivel de distrito o comuna, y obtuvo una variable de una imagen Landsat TM, verdor de la vegetación, la que fue integrada al sistema de información de datos censales. De esta forma, este autor plantea la necesidad de incorporar información de múltiples fuentes para generar sistemas de indicadores e índices más completos.

A pesar de la existencia de múltiples aplicaciones de imágenes de satélites para colectar datos sobre aspectos ambientales urbanos, la revisión no evidencia trabajos que integren distintos indicadores, derivados de las imágenes de satélite, para crear índices sintéticos que expliquen la complejidad espacial de la calidad ambiental urbana. En una ciudad como Cali, Colombia, con una población de más de 2 millones de habitantes, los planificadores urbanos no han usado información derivada de imágenes satelitales como fuente de datos para valorar la calidad ambiental. Por tanto, el objetivo de este trabajo es desarrollar y probar un método para estimar un índice de calidad ambiental, a nivel de barrio, empleando cinco indicadores ambientales derivados de imágenes de satélite: TS, y los índices NDVI, de contenido de humedad en las hojas (LWCI), de suelos de diferencia normalizada (NSI) y de vegetación ajustado al suelo (SAVI); que sirva como insumo para los procesos de planificación y gestión ambiental en ciudades grandes y medianas. La construcción de un índice más robusto demandaría, además de la información satelital, datos censales obtenidos de mediciones directas (calidad de aire, residuos sólidos, ruido, etc.) que para este caso no se encuentran disponibles a nivel de barrio. De comprobarse la utilidad del método y modelo, este podrá ser replicado en otras ciudades.

\section{Área de estudio y datos usados}

La ciudad de Cali está ubicada al suroeste de la República de Colombia, entre los $3^{\circ}$ $20^{\prime}$ y $3^{\circ} 30^{\prime}$ de latitud Norte y $76^{\circ} 27^{\prime}$ y $76^{\circ}$ $33^{\prime}$ de longitud Oeste, en el departamento del Valle del Cauca (Figura $N^{0} 1$ ). En términos fisiográficos, la ciudad se localiza en el valle del río Cauca, limitada por la cordiIlera Occidental al oeste, por el río Cauca al este, por la zona industrial del municipio de Yumbo al norte y por el área rural del municipio de Cali al sur. Es precisamente en esta última dirección hacia donde la ciudad sufre su mayor expansión. La altitud varía entre los 940 metros, próximo al río Cauca, y los 1.050 metros, en barrios ubicados en la cordillera. El clima es seco tropical, con una precipitación anual promedio de 1.477 mm y temperatura promedio anual de $24,1^{\circ}$ C. Para el año 2003, la ciudad cubría una extensión aproximada de $120 \mathrm{~km}^{2}$, con una población de 2,35 millones de habitantes (DAP, 2004).

Para esta investigación se utilizó parte de la imagen Landsat ETM+ identificada con el código 58-09 (Path y Row), fechada el 2 de enero de 2003. La imagen fue obtenida del servidor de la Universidad de Maryland, con un nivel de corrección 1G (con corrección tanto geométrica como radiométrica); había sido remuestreada por el método de convolución cúbica, con un tamaño de pixel de 30 metros para las bandas 1 a 5 y 7, 60 metros para las bandas 6,1 y 6,2 (termales) y 15 metros para la banda 8 (pancromática). El sector de la imagen correspondiente al perímetro urbano de la ciudad de Cali, área de trabajo, fue obtenido utilizando una capa de corte denominada bitmap. Todo el procesamiento digital de la imagen se realizó con el programa PCI Geomática 9,2. No se utilizaron imágenes de otras fechas, por cuanto este estudio, de carácter espacial, pretende evaluar cómo algunos factores de la calidad ambiental cambian como consecuencia de las diferencias de la estructura urbana de la ciudad, representada a nivel de tipologías de barrios.

Adicionalmente, se utilizaron dos mapas vectoriales de la ciudad de Cali: el de calles y vías, usado para hacer la corrección geométrica de la imagen, de manera que permitiera la correcta superposición con dicho mapa; y el de barrios, usado para obtener estadísticas de los indicadores ambientales de las imágenes por superposición. Ambos mapas fueron obtenidos de la Oficina de Planeación del municipio de Cali. 
Figura $\mathrm{N}^{\circ} 1$

Localización de la ciudad de Cali en el municipio de Cali, en el departamento del valle del Cauca y en Colombia

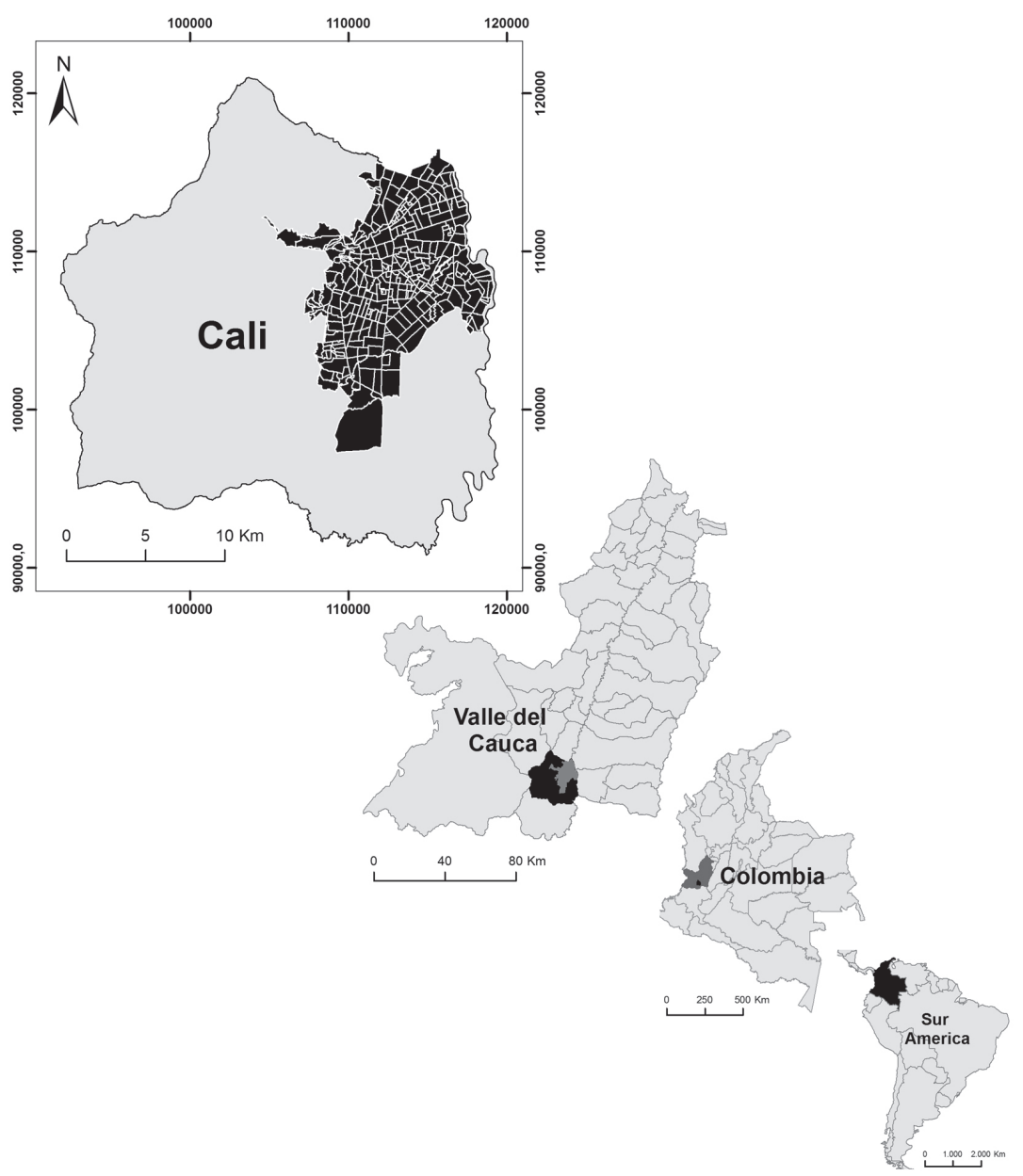

Fuente: Elaboración propia.

\section{Metodología}

En la Figura $\mathrm{N}^{\circ} 2$ se muestra el procedimiento seguido para construir el índice de calidad ambiental urbana propuesto. La descripción detallada de cada una de las etapas realizadas aparece a continuación.

Corrección geométrica y procesamiento digital de la imagen

Previo a la obtención de los indicadores ambientales temáticos necesarios para la construcción del ICA, la imagen ETM+ fue sometida a tres procesos fundamentales: corrección geométrica, conversión de los niveles digitales (ND) de las bandas espectrales no térmicas a valores de reflectividad, y conversión de los ND de las bandas térmicas a temperatura de superficie. La imagen no fue corregida atmosféricamente, debido a que no se contaba con el perfil atmosférico del día de toma de la imagen; sin embargo, esta fue adquirida bajo buenas condiciones atmosféricas.

Respecto a la corrección geométrica, la imagen fue proyectada con el sistema UTM, 
zona 18 Norte, WGS84. Para su correcta superposición al mapa de barrios de la ciudad, la imagen fue rectificada en sus posiciones utilizando el mapa de calles y vías como referencia; se usaron 18 puntos de control y 4 de chequeos, lográndose, por medio de una función polinomial de segundo orden, un error medio cuadrático (RMSE) de 0,43 y 0,57 píxel en coordenadas $\mathrm{X}$ e $\mathrm{Y}$, respectivamente, error que es aceptable para procesos como este (Chuvieco, 2002). Para la asignación del ND correspondiente a cada píxel en la nueva posición, se utilizó el método de vecino más próximo, el que asegura la menor transformación de los ND originales.

Los ND de las bandas espectrales no térmicas fueron convertidos a radiancia espectral a nivel del sensor y luego a reflectividad, siguiendo los pasos que aparecen en Landsat Project Science Office (2008).

\section{Obtención de los indicadores ambientales}

Para obtener la temperatura de superficie, la radiancia espectral a nivel de sensor, banda térmica, fue transformada a temperatura de brillo del satélite, usando la ecuación 1 (Landsat Project Science Office, 2008):

$$
T_{L}=K_{2} / 1 \mathrm{n}\left(\left(K_{1} / L_{\lambda}\right)+1\right)
$$

Donde:

$T_{L}$ : temperatura de brillo en grados Kelvin, para una radiancia $L$;

$K_{1}$ : constante de calibración 1 en $W /$ $\left(m^{2 *} s r^{*} u m\right)$;

$K_{2}$ : constante de calibración 2 en grados Kelvin (adimensional);

$L_{\lambda}$ : radiancia espectral del sensor.

Esta temperatura de brillo está referida como la de un cuerpo negro; por tanto fue necesario introducir la emisividad de la superficie de la tierra, considerando los tipos de uso, para obtener la temperatura cinética de superficie. Dicha conversión fue hecha mediante la ecuación 2 (Weng et al., 2004):

$$
T S=T_{L} / 1+\left(\lambda * T_{L} / \rho\right) * \ln \varepsilon
$$

Donde:

TS : temperatura de superficie corregida con la emisividad;

$T_{L}$ : temperatura de brillo del satélite;

$\lambda$ : longitud de onda media de la banda termal considerada;

$\mathrm{p}=h^{*} \mathrm{c} / \sigma,\left(1,438^{*} 10^{-2} \mathrm{mK}\right)$, donde:

h : constante de Planck $\left(6,626 * 10^{-34} \mathrm{Js}\right)$,

$C$ : es la velocidad de la luz;

$\sigma$ : constante de Boltzman $\left(1,38 * 10^{-23} \mathrm{~J} / \mathrm{K}\right)$;

$\varepsilon \quad$ : emisividad de la superficie.

Figura $\mathrm{N}^{\circ} 2$

Procedimiento metodológico usado para obtener el índice de calidad ambiental urbano

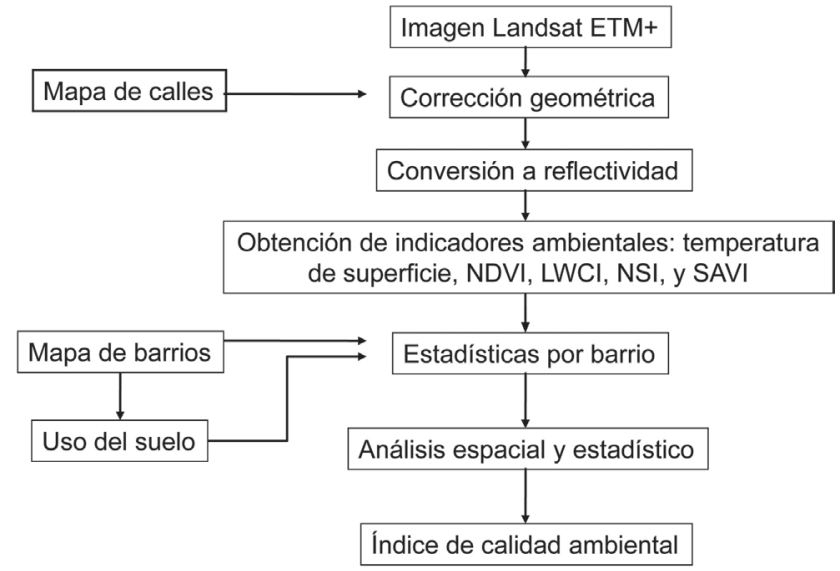

Fuente: Elaboración propia. 
La ecuación 3 permitió calcular la emisividad de las coberturas (Li et al., 2004):

$$
E=f_{v} \varepsilon_{v}+(1-f v) \varepsilon_{S}
$$

Donde:

$\varepsilon_{v}$ y $\varepsilon_{S}$ : emisividades de las cubiertas de vegetación y de suelo, respectivamente; se asumió que estas fueron de 0,985 y 0,978 , respectivamente;

$f_{v} \quad$ : fracción de vegetación, obtenida con la ecuación 4 por medio del NDVI, uno de los índices de vegetación más usado (Choudhury et al., 1994).

$f V=1-\left(\left(N D V I_{M A X}-N D V I\right) /\left(N D V I_{M A X}-N D V I_{M I N}\right)\right)^{a}(4)$

Donde:

$N D V I_{M A ́ x}$ : valor de NDVI máximo para la vegetación de mayor verdor;

NDVI $I_{\text {IN }}$ : NDVI mínimo presente en suelo desnudo.

A pesar de que en la imagen de NDVI existían valores negativos (especialmente en superficies de agua y nubes) se consideró un valor mínimo de 0 . El exponente a es un valor que depende de la orientación de las hojas de las plantas, y se tomó un valor de 0,6 (Li et al., 2004).

Finalmente la temperatura de superficie corregida con la emisividad (TS), en grados Kelvin, fue convertida a grados Celsius sustrayendo el valor de 273 a todos los píxeles de la imagen de TS.

Además de la temperatura de superficie, se obtuvieron los otros indicadores ambientales (NDVI, LWCI, NSI y SAVI), producto de la transformación de la imagen ETM+.

NDVI ha sido reconocido como uno de los indicadores más útiles para el estudio de características de la biosfera terrestre y su dinámica, a nivel global, regional y local (Chuvieco, 2002). Se obtiene de la ecuación (5):

$$
N D V I=(N I R-R) /(N I R+R)
$$

Donde NIR y $\mathrm{R}$ denotan la reflectividad del infrarrojo cercano (NIR) y rojo (R), respectivamente, de la imagen Landsat ETM+.
El índice LWCI, propuesto por Hunt et al. (1987) se basa en la interrelación entre las reflectividades en el infrarrojo de onda corta (SWIR) y en el NIR. Fue obtenido aplicando la ecuación (6):

$L W C I=-\log [1-(N I R-S W I R)] /-\log \left[1-\left(N I R_{F T}-S W I R_{F T}\right)\right](6)$

Donde NIR $_{\mathrm{FT}}$ y SWIR $\mathrm{ST}_{\mathrm{FT}}$ representan las reflectividades de la energía en el infrarrojo cercano y de onda corta, para las hojas con máxima presión turgor.

Para definir los valores de $\mathrm{NIR}_{\mathrm{FT}}$ y $\mathrm{SWIR}_{\mathrm{FT}}$ ambas bandas fueron cuidadosamente examinadas, con el fin de determinar la máxima reflectividad en la vegetación que crece en condiciones de alta humedad. Finalmente, 0,444 para NIR FT y 0,255 para SWIR FT fueron los más altos valores de reflectividad para vegetación verde expuesta a humedad continua, la cual se encontró en un pantano (laguna el Pondaje) ubicado en la parte oriental de la ciudad.

El índice de diferencia normalizada de suelos, propuesto por Roger y Kearney (2004), destaca las áreas construidas y en suelo desnudo, dado a que estas superficies son más reflectivas en el SWIR que en el NIR. Se obtuvo mediante la ecuación (7):

$$
N S I=(S W I R-N I R) /(S W I R+N I R)
$$

Finalmente se utilizó el índice SAVI, propuesto por Huete (1988), el cual es apropiado para regiones que tienen baja cubierta vegetal y consecuentemente alto porcentaje de reflectancia del suelo. Se obtuvo aplicando la ecuación (8):

$$
S A V I=[(N I R-R) /(N I R+R+L)](1+L)
$$

Siendo L un coeficiente de ajuste de la vegetación, equivalente a 0,5 , recomendado para densidades intermedias (Chuvieco, 2002).

Valores altos por píxel de NDVI y de SAVI, indican una presencia alta de vegetación, lo cual se corresponde normalmente con una mejor calidad ambiental, dado sus efectos benéficos en la purificación de agua y aire, disminución de ruido, por la sombra 
y valor escénico que aporta, y por la transferencia a la atmósfera, mediante la transpiración, del calor latente almacenado en el suelo, lo que ocasiona una disminución de la temperatura de superficie, entre otros. Para el caso del indicador LWCI, por tratarse de una variable altamente correlacionada con la vegetación, su comportamiento frente a la calidad ambiental es similar al planteado para NDVI y para SAVI. En cambio, los valores de NSI son más altos a medida que exista una mayor proporción de área construida o en asfalto (áreas impermeables), lo que determina una disminución de los efectos benéficos mencionados para los índices de vegetación, y un aumento de TS, por la mayor capacidad de absorción de calor y conductividad térmica de los materiales de las construcciones, con el posible aumento de demanda de aire acondicionado y en consecuencia de los niveles de contaminación (Yuan y Bauer, 2007); es decir, a mayores valores de NSI y de TS, menor calidad ambiental.

Considerando que en muchas ciudades el barrio constituye la unidad espacial básica para la obtención de datos y para la gestión y planificación, se obtuvo un valor promedio por barrio de cada uno de los indicadores ambientales, mediante la superposición del mapa de barrios a los datos raster de TS, NDVI, LWCI, NSI y SAVI, realizada con el programa $\mathrm{PCI}$ Geomática. Todos estos datos fueron exportados al software SPSS, para análisis estadísticos posteriores.

No se contaba con una clasificación de uso del suelo de los barrios de la ciudad, pues esta información no existe como tal en la Oficina de Planeación Municipal. Por ello, todos los barrios y áreas especiales fueron clasificados en clases de uso del suelo (Cuadro $\mathrm{N}^{\circ}$ 1) siguiendo tres criterios: 1) la estructura y densidad de construcciones, 2) el estrato socioeconómico y nivel general de ingresos, y 3) la funcionalidad del barrio o área especial, aspecto que se derivó del conocimiento experto de la ciudad. Con la obtención de clases de uso del suelo se buscaba agrupar polígonos similares en cuanto a estructura de construcción y densidad de viviendas, presencia o ausencia de zonas con vegetación, funcionalidad, entre otros; y analizar la variación de los promedios de los indicadores ambientales, según las clases de uso urbano, y consecuentemente validar la existencia o no de diferencias estadísticas significativas del ICA entre las clases de uso del suelo, empleando análisis de varianza -ANOVA-. La representación cartográfica de las clases de uso del suelo se realizó utilizando el sistema de información geográfica ArcGis 9.0.

\section{Estimación del índice de calidad ambiental urbano}

Partiendo de la idea de que los cinco indicadores ambientales analizados guardan una estructura de correlación alta, se utilizó un análisis de componentes principales (ACP) con el fin de determinar las dimensiones subyacentes (componentes) en los promedios de los indicadores ambientales obtenidos para cada uno de los barrios. Previo a la realización del ACP, se examinó que los cinco indicadores mostraban una distribución normal. La extracción de componentes se realizó considerando la matriz de correlación, reteniendo aquellos componentes, por el método de regresión, con autovalor (eigenvalues) mayor a 1, valor recomendado por Johnson (1998) para que se retenga al menos una de las variables de entrada.

La obtención del índice (primer componente retenido) permitió crear un mapa donde se muestra su comportamiento en cada uno de los barrios y áreas especiales, en desviaciones típicas respecto al promedio de la ciudad, con el que se pudo: establecer una escala cualitativa de calidad ambiental, adoptando las clases muy deficiente, deficiente, regular, buena y muy buena, propuestas por Escobar (2006); conocer patrones geográficos de distribución de la calidad ambiental en la ciudad; e identificar los barrios o áreas especiales que presentan situaciones críticas o aceptables de calidad ambiental. De esta forma, la información derivada puede ser usada por los tomadores de decisiones, para la planificación y gestión ambiental urbana.

\section{Pruebas de significancia estadística del índice de calidad ambiental}

Con las estadísticas promedios del ICA por barrio y luego por clases de uso urbano obtenidas con el ACP, se realizó un análisis de varianza simple y múltiple (post-hoc) para 
conocer cómo varía el ICA según la clase de uso urbano, si existen diferencias estadísticas significativas entre los valores promedios del ICA según la clase de uso urbano y, de existir diferencias estadísticas significativas, determinar entre cuáles pares de clases de uso urbano ocurren. Previo a la realización del ANOVA se comprobó la homogeneidad o no de varianza de los promedios por barrio del ICA, usando el estadístico de Levene.

\section{Resultados}

\section{Características de los indicadores} ambientales obtenidos de la imagen ETM+

El comportamiento espacial de los indicadores ambientales obtenidos de la imagen se muestra en la Figura $N^{0} 3$. Es importante resaltar que Cali es una ciudad con una estructura urbana reticular donde las zonas con mayor proporción de área construida aparecen hacia el centro de la imagen, las que corresponden a los barrios del centro administrativo y comercial, y hacia el oriente de la imagen, en el sector denominado distrito de Agua Blanca, donde se encuentran barrios habitacionales con desarrollo no planificado y ocupado por población de muy bajos niveles de ingreso. Las áreas que tienen mayor proporción de vegetación se encuentran hacia el sur de la ciudad, correspondientes a barrios ocupados por población con los mayores niveles de ingreso y donde existe la mayor concentración de parques y zonas verdes. Hacia el oriente de la ciudad, por fuera del perímetro urbano, se destaca el río Cauca, el que, como se dijo anteriormente, marca el límite de la ciudad en esa dirección.

Cuadro $\mathrm{N}^{\circ} 1$

Descripción de las clases de uso de suelo urbano para la ciudad de Cali, 2003

\begin{tabular}{|c|c|c|c|}
\hline $\begin{array}{l}\text { Clase de uso } \\
\text { del suelo }\end{array}$ & Descripción & $\begin{array}{l}\text { Número de } \\
\text { polígonos }\end{array}$ & $\begin{array}{l}\text { Área } \\
(\%)\end{array}$ \\
\hline $\mathrm{H} 1$ & $\begin{array}{l}\text { Habitacional 1: muy alta densidad de construcciones y } \\
\text { con habitantes de muy bajos ingresos económicos }\end{array}$ & 100 & 21 \\
\hline $\mathrm{H} 2$ & $\begin{array}{l}\text { Habitacional 2: alta densidad de construcciones y con } \\
\text { habitantes de bajos ingresos económicos }\end{array}$ & 118 & 27 \\
\hline $\mathrm{H} 3$ & $\begin{array}{l}\text { Habitacional 3: baja densidad de construcciones y con } \\
\text { habitantes de altos ingresos económicos }\end{array}$ & 36 & 11 \\
\hline $\mathrm{H} 4$ & $\begin{array}{l}\text { Habitacional 4: muy baja densidad de construcciones y } \\
\text { con habitantes de muy altos ingresos económicos }\end{array}$ & 14 & 11,4 \\
\hline $\mathrm{CH}$ & Comercial y habitacional próximo al centro administrativo & 11 & 3 \\
\hline $\mathrm{AC}$ & Centro administrativo y comercial & 1 & 0,003 \\
\hline$P Q$ & $\begin{array}{l}\text { Parques, universidad pública, clubes, bosques de } \\
\text { gallería y áreas verdes }\end{array}$ & 16 & 11,2 \\
\hline HPQ & $\begin{array}{l}\text { Barrios parcialmente construidos combinado con áreas } \\
\text { verdes }\end{array}$ & 39 & 14,9 \\
\hline $\mathrm{H}$ & Barrios históricos (antiguos), especialmente habitacional & 3 & 0,01 \\
\hline \multirow[t]{2}{*}{1} & Barrios industriales, con grandes y pequeñas industrias & 5 & 0,02 \\
\hline & Total & 343 & 100 \\
\hline
\end{tabular}

El área urbana total es de 120,23 km², aproximadamente.

Fuente: Elaboración propia. 
Considerando el comportamiento de los indicadores ambientales estudiados, las Figuras $\mathrm{N}^{\circ} 3$ a) y 3 d) muestran que la temperatura de superficie y NSI están fuertemente correlacionados; tonos más claros corresponden a mayores valores y viceversa. Los barrios con más alta temperatura promedio $\left(>30^{\circ}\right.$
C), como los ubicados en el centro administrativo y comercial y en el sector oriente, se corresponden con los más altos valores de NSI (mayor proporción de área construida y/o suelo desnudo). De otro lado, al analizar las Figuras $\mathrm{N}^{\circ} 3 \mathrm{~b}$ ) (NDVI), $\mathrm{N}^{\circ} 3 \mathrm{c}$ ) (LWCl) y $\mathrm{N}^{\circ}$ 3 e) (SAVI) se observa que estos tres indica-

Figura $\mathrm{N}^{\circ} 3$

Comportamiento espacial de los indicadores derivados de la imagen Landsat de Cali ${ }^{4}$

a) TS
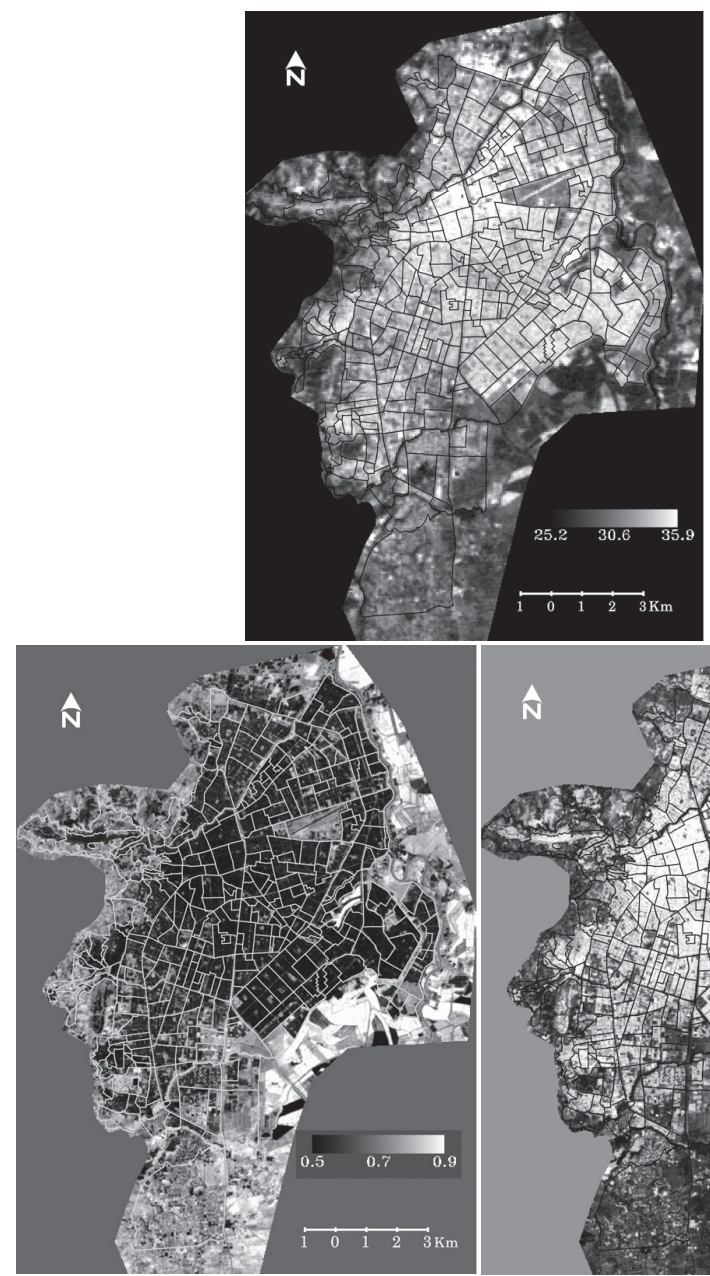

c) LWCI

b) NDVI

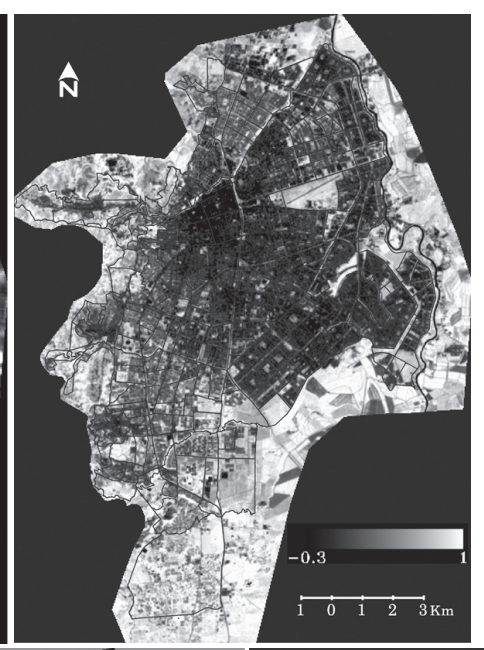

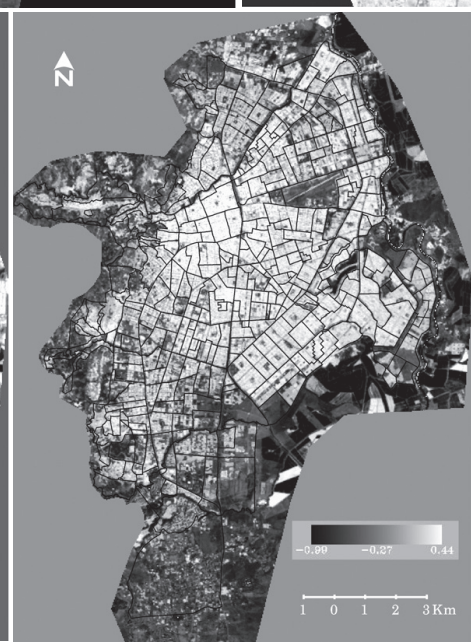

d) NSI

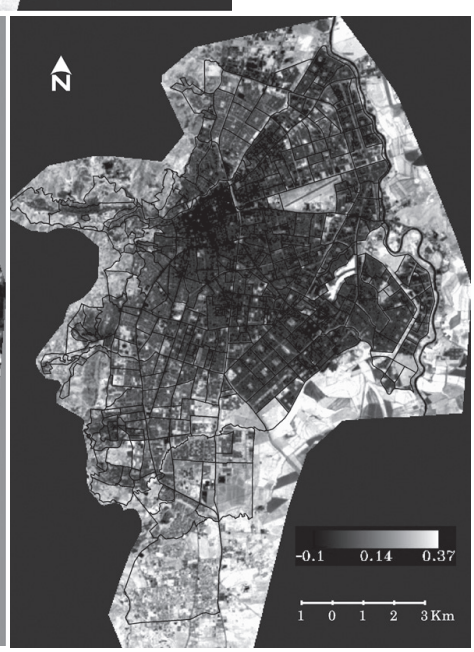

e) SAVI

Fuente: Elaboración propia en base al procesamiento de la imagen Landsat ETM+.

4 Los polígonos representan los barrios y áreas especiales. 
dores tienen un comportamiento parecido, donde los menores valores (tono oscuro a negro) se concentran en los barrios con mayor proporción de área construida ubicados en el centro y oriente de la ciudad, mientras los mayores valores (tonos claros) corresponden a los barrios de mayor proporción de áreas verdes, localizados en el sur, y ciertos sectores del occidente de la ciudad. El comportamiento tonal de estos últimos tres indicadores muestra una correlación inversa a TS y NSI. No obstante, la distribución espacial de los indicadores ambientales evidencia una alta correlación entre ellos, positiva o negativa, lo cual intuitivamente parece estar explicando un mismo fenómeno o variable latente: la calidad ambiental.

A partir de la información primaria de estratos socioeconómicos en que está dividida la ciudad (seis niveles), la densidad de viviendas y su ocupación o función, los 343 barrios y áreas especiales de la ciudad fueron clasificados en 10 clases de uso del suelo, cuya descripción se encuentra en el Cuadro $\mathrm{N}^{\circ} 1$. Para la fecha, se aprecia que aproximadamente la mitad del área (49\%) tiene un uso habitacional, con una muy alta a alta densidad de viviendas (clases $\mathrm{H} 1$ y H2, respectivamente), donde vive una población de muy bajo a bajos ingresos; en estas dos categorías se concentra el $64 \%$ del número total de barrios o áreas especiales. El 22\% del área y el 15\% del número total de polígonos lo ocupan barrios con baja a muy baja densidad de viviendas ( $\mathrm{H} 3$ y H4, respectivamente) y donde se asienta una población con altos a muy altos ingresos. El 15\% del área de la ciudad corresponde a barrios en proceso de construcción de viviendas y el $11 \%$ pertenece a parques y zonas verdes. Las clases centro administrativo y comercial (AC), barrios antiguos o históricos $(\mathrm{H})$ e industriales (I) ocupan menos del 0,5\% del área de la ciudad. La clasificación de los distintos barrios y áreas especiales de la ciudad, según el uso del suelo, permite comprender la lógica que explica la distribución espacial de los valores promedios de los indicadores ambientales y, como consecuencia de ello, del ICA estimado. La localización espacial de cada una de las clases de uso del suelo se muestra en la Figura $N^{\circ} 4$.

Al contrastar la distribución de los indicadores ambientales (Figura № 3 ) con las clases de uso del suelo (Figura $\mathrm{N}^{\circ} 4$ ) se aprecia que los mayores valores de NSI y temperatura de superficie y menores de NDVI, LWCI y SAVI ocurren en las clases centro administrativo y comercial (AC) y comercial-habitacional $(\mathrm{CH})$, ubicados en el centro de la ciudad y en los barrios habitacionales de las clases $\mathrm{H} 1$, $\mathrm{H} 2$ y $\mathrm{H}$, localizados en el distrito de Agua Blanca (zona oriental) donde se localizan los barrios con los más bajos estratos socioeconómicos. En cambio, los mayores valores de NDVI, LWCI y SAVI, y consecuentemente menores valores de TS y NSI, ocurren en la clase $\mathrm{H} 4$, ubicada principalmente al sur y en algunos barrios al occidente de la ciudad, así como en parques y áreas verdes (PQ) y zonas habitacionales en expansión (HPQ), localizadas mayormente al sur y en pequeñas zonas de la cordillera Occidental.

En la Figura $N^{\circ} 5$ se muestran imágenes de algunos sectores de la ciudad, considerando la clase de uso del suelo. Es claro que existen contrastes marcados entre la estructura urbana de dichos sectores, evidenciando el caracter segregado de ciertos barrios en la ciudad. Por ejemplo, los barrios habitacionales con muy alta densidad de construcciones -H1- (Figura $\mathrm{N}^{\circ} 5 \mathrm{a}$ ), comercial y habitacional - $\mathrm{CH}$ - (Figura $\mathrm{N}^{\circ} 5$ b) y administrativo y comercial -AC- (Figura $\mathrm{N}^{\circ} 5$ e) muestran una malla vial reticular y con la casi ausencia completa de vegetación. Se diferencian en que en $\mathrm{H} 1$ las construcciones son bajas y las calles son muy estrechas (callejones), características propias de barrios marginales; en $\mathrm{CH}$, en cambio, las manzanas tienen unas dimensiones cuadradas, con la presencia de calles más amplias (producto de un proceso de planificación ordenado) y edificaciones medianas a grandes; en $\mathrm{AC}$ predominan los edificios altos y al igual que en $\mathrm{CH}$ la estructura de manzanas y vías es ordenada. En los sectores que muestran barrios habitacionales con baja y muy baja densidad de construcciones $-\mathrm{H} 3$ y $\mathrm{H} 4$, respectivamente-, representados en las Figuras $\mathrm{N}^{\circ} 5$ c) y $\mathrm{N}^{\circ} 5 \mathrm{~d}$ ), y en el campus de la Universidad del Valle (Figura $\mathrm{N}^{\circ} 5 \mathrm{f}$ ), se aprecia un diseño vial con intersecciones algo oblicuo, con presencia de parques y con un aumento notable de vegetación arbórea y herbácea (zonas verdes), lo cual indica una estructura de planificación donde el componente ambiental es un eje o elemento estructurante del diseño urbano. 
En el Cuadro $\mathrm{N}^{\circ} 2$ se presentan las estadísticas centrales de los indicadores TS, NDVI, LWCI, NSI y SAVI analizados, para cada una de las clases de uso del suelo presentes en la ciudad. Los más altos valores promedios de NDVI, LWCI y SAVI, como se esperaba, aparecen en las clases PQ y H4, que son las unidades que tienen mayor pro- porción de áreas verdes, mientras los menores se encuentran en el centro administrativo de la ciudad (AC) y en los barrios de viviendas antiguos $(\mathrm{H})$ y con industrias (I). La mayor homogeneidad de los promedios de estos indicadores, menor desviación típica, ocurre en los barrios antiguos $(\mathrm{H})$, mientras en los de baja densidad de construcciones ( $\mathrm{H} 4)$

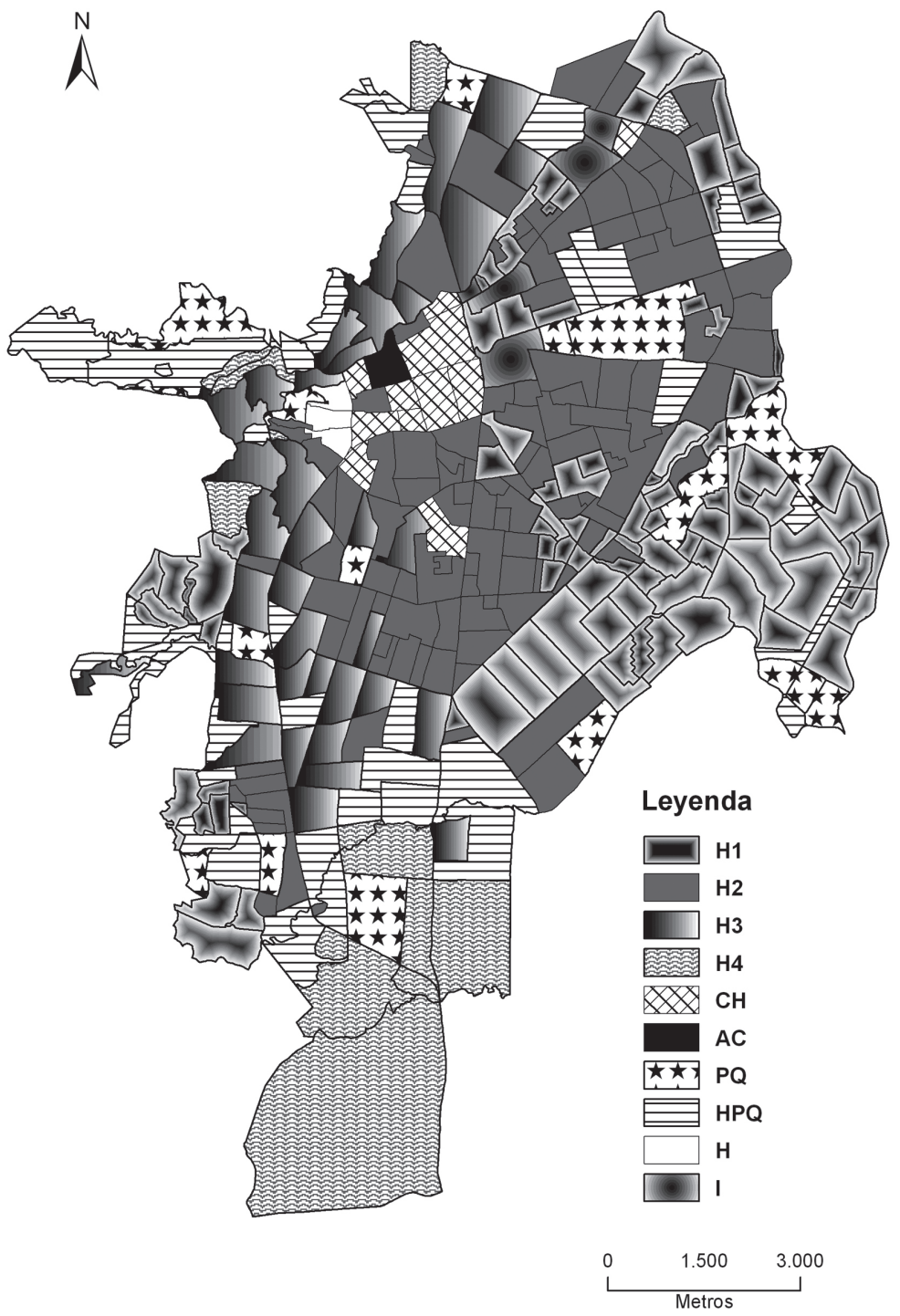

Fuente: Elaboración propia. 
existe mayor heterogeneidad. Considerando los promedios de NSI y TS por clases de uso, los mayores valores se dan en los barrios con carácter comercial-habitacional $(\mathrm{CH})$ y los menores en $\mathrm{PQ}$ y $\mathrm{H} 4$; los barrios con mayor homogeneidad en estos últimos indicadores se agrupan en la clase de uso $(\mathrm{H})$, y los de mayor heterogeneidad ocurren en $\mathrm{H} 4$ para NSI y en PQ para TS.

El comportamiento de los indicadores ambientales analizados, especialmente la relación entre NDVI y $\mathrm{LWCl}$ y SAVI con la temperatura de superficie, concuerda con estudios anteriores, en el sentido de que mayores niveles del índice de vegetación y menores de suelo construido o desnudo se corresponden con una más baja temperatura de superficie (Weng, 2001; Chen, 2006; Santana, 2007). No obstante, la relación positiva fuerte entre TS y NSI no había sido reportada previamente.
Índice de Calidad Ambiental: interpretación del análisis de componentes principales

El Cuadro $\mathrm{N}^{\circ} 3$ muestra los resultados del análisis de correlación de Pearson realizado, considerando los valores promedios por cada barrio de los cinco indicadores ambientales utilizados en el estudio. Se aprecian tres comportamientos distintos: las variables NDVI, LWCI y SAVI tienen una muy alta correlación positiva entre ellas; de igual modo, TS y NSI tienen una alta correlación positiva; y los tres primeros indicadores respecto a los dos últimos, revelan una alta correlación negativa. Estos resultados concuerdan con el comportamiento tonal de los indicadores ambientales vistos en la Figura $N^{\circ} 2$ y hacen propicio, por su alta correlación positiva y/o negativa, la aplicación de un análisis de componentes principales, que permita encontrar las dimensiones subyacentes contenidas en dichos indicadores.

\section{Cuadro $\mathrm{N}^{\circ} 2$}

Promedio (Prom) y desviación típica (D. T.) de los indicadores ambientales, según clase de uso urbano

\begin{tabular}{|l|c|c|c|c|c|c|c|c|c|c|}
\hline \multirow{2}{*}{$\begin{array}{l}\text { Uso del } \\
\text { suelo }\end{array}$} & \multicolumn{2}{|c|}{ TS } & \multicolumn{2}{c|}{ NDVI } & \multicolumn{2}{c|}{ LWCI } & \multicolumn{2}{c|}{ NSI } & \multicolumn{2}{c|}{ SAVI } \\
\cline { 2 - 10 } & Prom & D.T. & Prom & D.T. & Prom & D.T. & Prom & D.T. & Prom & D.T. \\
\hline H1 & 31,45 & 0,749 & 0,159 & 0,108 & $-0,166$ & 0,079 & 0,147 & 0,067 & 0,053 & 0,038 \\
H2 & 31,44 & 0,744 & 0,177 & 0,118 & $-0,158$ & 0,085 & 0,153 & 0,072 & 0,053 & 0,04 \\
H3 & 30,34 & 0,928 & 0,352 & 0,108 & $-0,061$ & 0,071 & 0,064 & 0,062 & 0,104 & 0,038 \\
H4 & 29,24 & 0,925 & 0,507 & 0,149 & 0,057 & 0,115 & $-0,032$ & 0,084 & 0,164 & 0,059 \\
CH & 32,14 & 0,896 & 0,05 & 0,081 & $-0,231$ & 0,06 & 0,24 & 0,068 & 0,013 & 0,021 \\
AC & 30,63 & $-*$ & 0,041 & - & $-0,189$ & - & 0,236 & - & 0,01 & - \\
PQ & 29,34 & 1,196 & 0,546 & 0,118 & 0,117 & 0,088 & $-0,073$ & 0,059 & 0,191 & 0,036 \\
HPQ & 29,71 & 1,095 & 0,471 & 0,146 & 0,043 & 0,113 & $-0,02$ & 0,081 & 0,158 & 0,056 \\
H & 31,85 & 0,153 & 0,124 & 0,01 & $-0,253$ & 0,007 & 0,23 & 0,006 & 0,035 & 0,002 \\
I & 31,99 & 0,767 & 0,174 & 0,075 & $-0,131$ & 0,052 & 0,15 & 0,049 & 0,048 & 0,022 \\
\hline
\end{tabular}

* La clase AC tiene tan solo un (1) polígono, por tanto no tiene dispersión.

Fuente: Elaboración propia. 
Figura $\mathrm{N}^{\circ} 5$

Imágenes de algunos sectores de Cali, según la clase de uso del suelo ${ }^{5}$
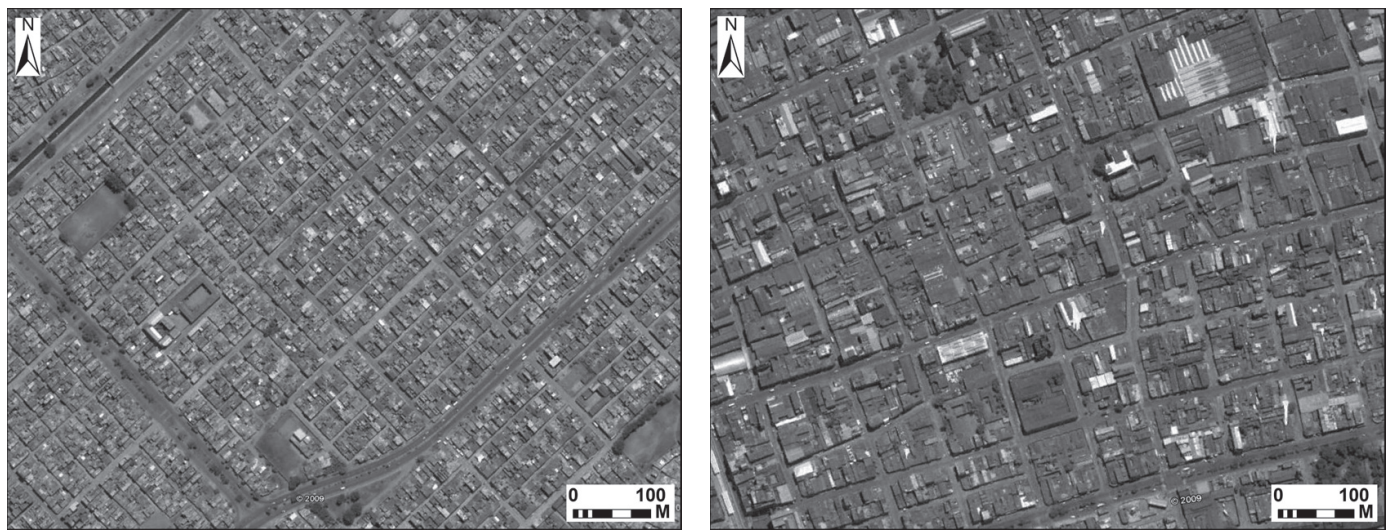

a) $\mathrm{H} 1$ (barrios El Vergel, El Poblado)
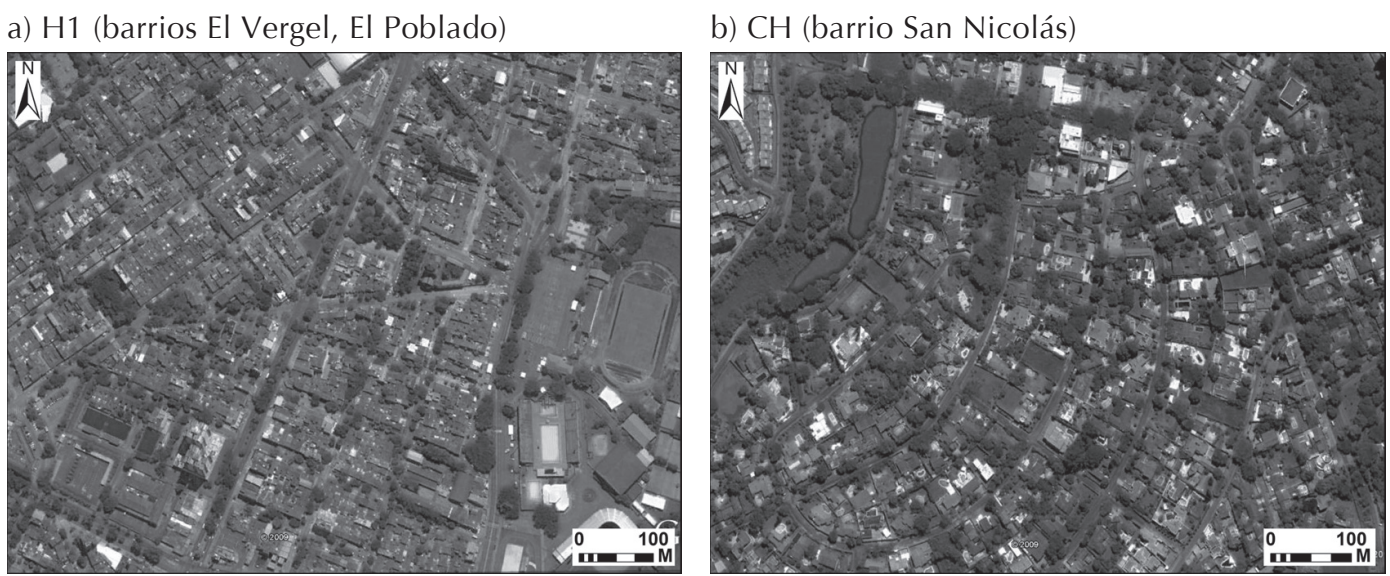

d) H4 (barrio Ciudad Jardín)
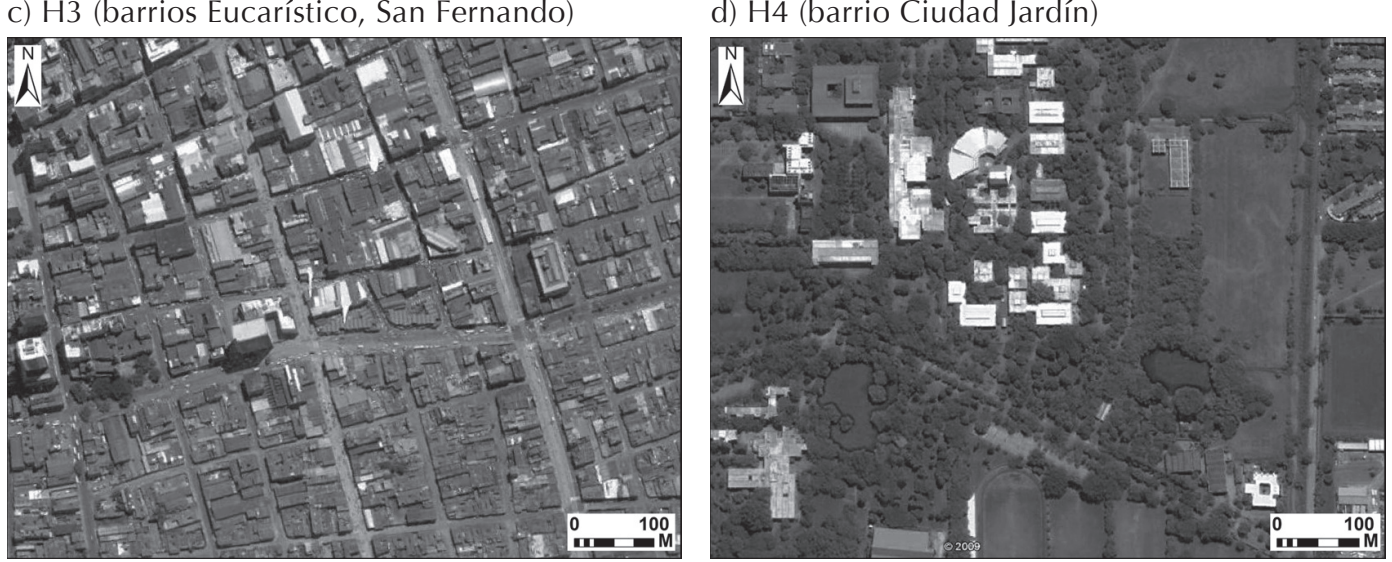

e) AC (barrios San Pedro, El Calvario)

f) PQ (Campus Universidad del Valle)

Fuente: Google Earth; imagen de Digital Globe del 1 de julio de 2007.

5 Las calles y edificaciones aparecen con tonos gris a blanco, mientras la vegetación y lagos muestran tono gris oscuro; nótese además la configuración de la red de calles. 
Cuadro $\mathrm{N}^{\circ} 3$

Análisis de correlación de Pearson entre pares de indicadores ambientales

\begin{tabular}{|l|c|c|c|c|c|}
\hline & TS & NDVI & LWCI & NSI & SAVI \\
\hline TS & 1 & $-0,896^{*}$ & $-0,876^{*}$ & $0,894^{*}$ & $-0,871^{*}$ \\
NDVI & & 1 & $0,970^{*}$ & $-0,977^{*}$ & $0,987^{*}$ \\
LWCI & & & 1 & $-0,985^{*}$ & $0,979^{*}$ \\
NSI & & & & 1 & $-0,979^{*}$ \\
SAVI & & & & & 1 \\
\hline
\end{tabular}

* Significancia estadística de dos colas al 99\%. Fuente: Elaboración propia.

La aplicación del ACP, con los valores promedios por barrio de los cinco indicadores estudiados, basado en la regla de que se retendrían componentes con autovalores mayores a uno, permitió generar un componente (índice propuesto) que almacena el $95 \%$ de la varianza contenida en los cinco indicadores de entrada. Con el propósito de hacer una mejor interpretación, el componente extraído fue rotado usando la función Varimax (Cuadro $N^{\circ} 4$ ). El valor obtenido (loadings) expresa la correlación entre los indicadores de entrada y el índice o componente obtenido. Así, el índice obtenido tiene una muy alta correlación positiva $(>0,98)$ con NDVI, LWCI y con SAVI, lo que denota la contribución positiva o efectos benéficos de la vegetación y de su contenido de humedad en las hojas y una muy alta correlación negativa $(>0,92)$ con NSI y TS, lo que demuestra la contribución negativa al índice de las áreas construidas, vías, suelo desnudo y consecuentemente áreas con alta temperatura. La comunalidad de todos los indicadores (cantidad de varianza que cada indicador comparte con los demás) es muy alta, siendo TS la que muestra el menor valor $(0,86)$. Como se aprecia, la correlación obtenida, ya sea positiva o negativa, entre los indicadores ambientales de entrada y el componente principal extraído, supera el valor de 0,92, estando muy por encima del valor de 0,71 recomendado como excelente por Li \& Weng (2005). Por tanto, el componente obtenido refleja sintéticamente la calidad ambiental a nivel de barrio, y como tal puede ser uti- lizado por las entidades territoriales para la gestión ambiental urbana.

La distribución espacial del ICA se muestra en la Figura $N^{\circ}$ 6. La calidad ambiental muy buena (ICA $>2$ desviaciones típicas, respecto al promedio) ocurre predominantemente en barrios que tienen una alta proporción de vegetación arbórea y/o herbácea y baja de área construida, pertenecientes a las clases de uso $\mathrm{H} 4$ y $\mathrm{PQ}$, ubicadas al sur y occidente de la ciudad; con valores del ICA entre 1 y 2 desviaciones por encima del promedio, calidad ambiental buena, se encuentran barrios pertenecientes mayormente a las clases de uso HPQ y H3; y con calidad ambiental regular aparecen barrios con ICA entre 0 y 1 desviación típica por encima del promedio, ubicados principalmente en la clase de uso H3. En cambio, la calidad ambiental muy deficiente aparece en áreas con los valores más bajos del ICA (-1 a -1,64 desviaciones típicas respecto al promedio), los que se ubican mayoritariamente en barrios clasificados como comercial-habitacional $(\mathrm{CH})$, administrativo-comercial (AC), habitacional con muy alta y alta proporción de construcciones $(\mathrm{H} 1-\mathrm{H} 2)$ e industrial (I), ubicados en el centro y oriente de Cali; con calidad ambiental deficiente aparecen barrios con valor del ICA entre 0 y -1 desviación típica respecto al promedio, se encuentran otros barrios clasificados en las categorías de uso habitacional con muy alta y alta proporción de construcciones ( $\mathrm{H} 1$ y $\mathrm{H} 2$, respectivamente). 
Significancia estadística del ICA según las clases de uso del suelo

El análisis de varianza simple aplicado al ICA obtenido para cada uno de los barrios mostró diferencias estadísticas significativas, considerando toda la ciudad. Los resultados del análisis múltiple (post-hoc), utilizando la prueba Game-Howell, recomendada en casos de heterogeneidad de la varianza (PardoMerino y Ruiz-Díaz, 2002), se muestran en el Cuadro $N^{\circ} 5$. De las 36 posibles combinaciones bivariadas entre las clases de uso del suelo urbano, 24 mostraron diferencias estadísticas significativas. Los valores promedios del ICA para las clases $\mathrm{H} 1$ y $\mathrm{H} 2$ (las que son estadísticamente similares) son significativamente peores que los de $\mathrm{H} 3, \mathrm{H} 4, \mathrm{PQ}$ y HPQ y significativamente mejores que los de $\mathrm{CH}$; pero no mostraron diferencias estadísticas significativas respecto a $\mathrm{H}$ e I. La clase $\mathrm{H} 3$ fue estadísticamente peor que H4, PQ y HPQ (clases con mayor proporción de áreas verdes) y estadísticamente mejor que $\mathrm{CH}$ y $\mathrm{H}$. Los valores promedios del ICA de $\mathrm{H} 4$ son mayores que el resto de las clases, excepto $P Q$, aunque frente a PQ y HPQ no muestra diferencias estadísticas significativas. La clase de uso con menor promedio del ICA es $\mathrm{CH}$, aunque no muestra diferencia estadística significativa frente a $\mathrm{H}$ e I; en cambio, las clases con mayores valores son $\mathrm{PQ}$ y HPQ, las que no muestran diferencia estadística entre ellas. No se evidencia diferencia estadística significativa entre las clases $\mathrm{H} \mathrm{e} \mathrm{I}$; no obstante, esto puede deberse al bajo número de barrios o polígonos que tienen estas dos clases, 3 y 5 , respectivamente.

\section{Consideraciones finales}

Del estudio se derivaron cinco indicadores temáticos (TS, NDVI, LWCI, NSI y SAVI) estimados a partir de una imagen satelital Landsat ETM+. Los resultados son consistentes al mostrar que los indicadores NDVI, LWCI y SAVI están correlacionados entre sí, y tienen una correlación fuerte y positiva con los barrios y áreas especiales donde existe alta proporción de vegetación; en tanto que NSI y TS, altamente correlacionados, presentan una correlación positiva con las áreas que tienen mayor proporción de área construida y vías. Estos comportamientos coinciden con la literatura de referencia, en la medida que explica cuantitativamente la relación espa-

Cuadro $\mathrm{N}^{\circ} 4$

Resultados del análisis de componentes principales realizado con los indicadores ambientales

\begin{tabular}{|l|c|c|}
\hline \multicolumn{1}{|c|}{ Indicador } & Componente & Comunalidad* \\
\hline NDVI & 0,99 & 0,979 \\
LWCI & 0,986 & 0,972 \\
NSI & $-0,991$ & 0,982 \\
SAVI & 0,987 & 0,974 \\
TS & $-0,928$ & 0,861 \\
\hline Autovalor 4,8 & \\
Porcentaje de varianza 95,4 & \\
* Comunalidad: porcentaje de información compartida con los otros indicadores \\
Método de extracción: Regresión, con rotación Varimax \\
Determinante: 4,068E-06 \\
KMO: 0,865
\end{tabular}

Fuente: Elaboración propia. 
cial entre las variables estimadas y la forma como se utiliza el suelo urbano de la ciudad. Del análisis integrado de los indicadores se derivó un índice sintético de calidad ambiental que recoge el $95 \%$ de la varianza, y que responde de manera positiva a los efectos benéficos de la vegetación, y de manera ne- gativa a los efectos adversos de la ciudad de cemento.

De la espacialización del ICA se evidencia que es en los barrios con valores de desviación típica entre -1 y -1,64 respecto al promedio (San Nicolás, El Calvario, Sucre, El Vergel,

Figura $N^{\circ} 6$

Comportamiento espacial del índice de calidad ambiental, desviación típica respecto al promedio y clase de calidad ambiental, para los distintos barrios de la ciudad de Cali

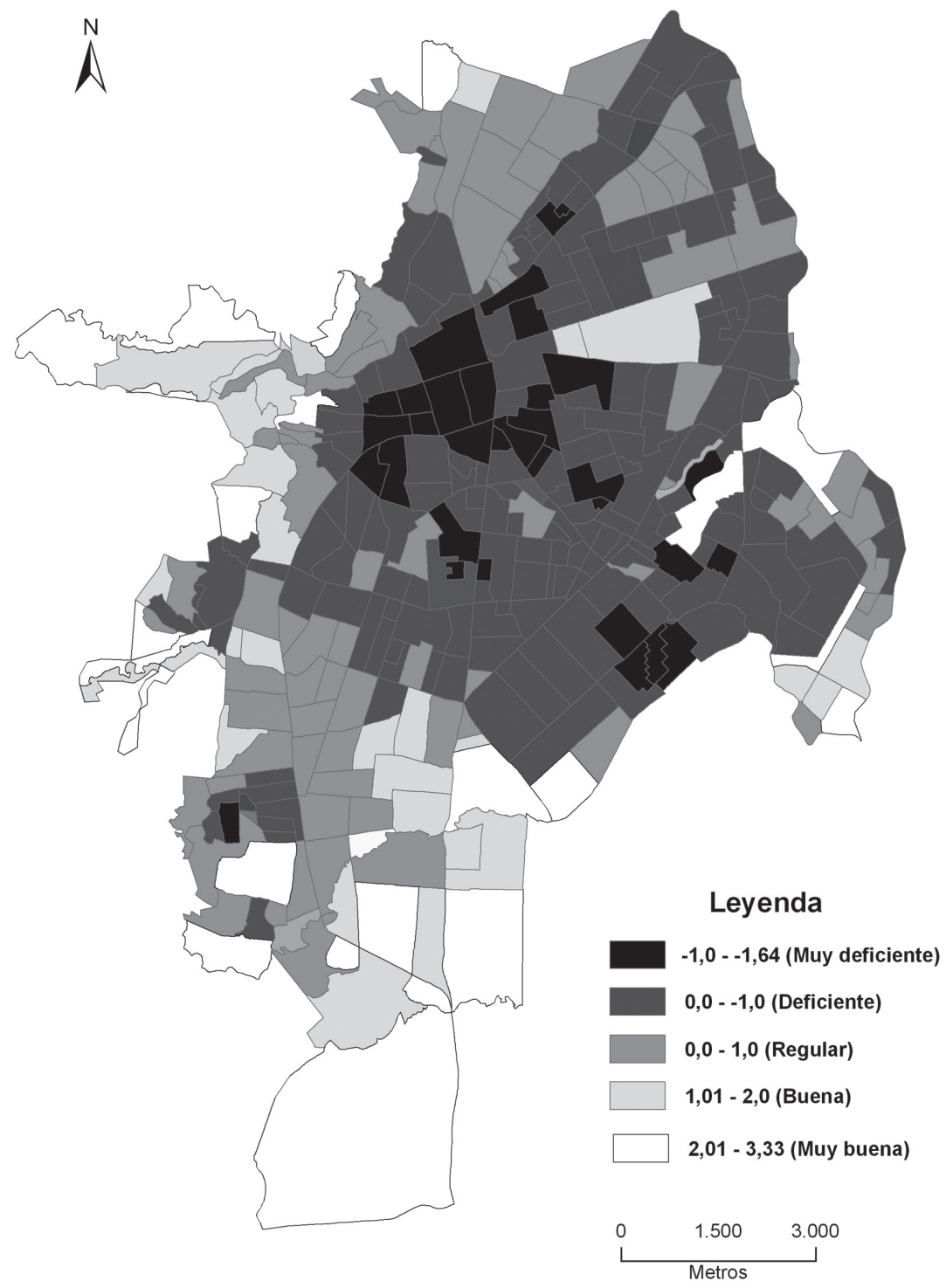

Fuente: Elaboración propia. 
El Retiro, entre otros, pertenecientes a las clases de uso $\mathrm{CH}, \mathrm{I}$ y $\mathrm{H} 1$ ) donde se requiere, en términos relativos, una pronta intervención de las instituciones de planificación urbana, para aumentar las condiciones de calidad de vida, a partir del mejoramiento de la calidad ambiental muy deficiente. En orden de prioridad de las acciones de intervención, le siguen los barrios con calidad ambiental deficiente, con ICA entre 0 y - 1 desviación típica (mayoritariamente pertenecientes a las clases $\mathrm{H} 1$ y $\mathrm{H} 2$ ). De otro lado, en los barrios que muestran un ICA entre 1 y 3,3 desviaciones típicas por encima del promedio, calidad ambiental buena y muy buena, se debe procurar al menos mantener las condiciones de proporción de vegetación respecto a las áreas construidas y el diseño urbano.

Aun cuando la calidad ambiental está determinada por una cantidad amplia de variables o indicadores, los datos contenidos en las imágenes de satélite Landsat recogen información latente relacionada con las construcciones (densidad, tipos de materiales, zonas impermeables, entre otros), vías, espacios abiertos, tipos de vegetación y con los procesos de intercambio de energía en- tre la superficie y la atmósfera. Para avanzar en el desarrollo del proceso metodológico expuesto, el ICA estimado necesariamente debe ser complementado, incorporando otros indicadores obtenidos de mediciones directas (residuos sólidos, ruido, densidad de tráfico, biodiversidad, calidad de agua y del aire, etc.), a nivel de barrio, pero en una ciudad como Cali y seguramente muchas otras de los países en vías de desarrollo, estas estadísticas a nivel de barrio no existen.

Probada la funcionalidad de la metodología para la construcción del ICA, Ios planificadores ambientales urbanos tienen una importante herramienta para derivar información espacio-temporal que, combinada con datos e indicadores censales de otros factores ambientales urbanos, contribuya a la caracterización de la línea base para la definición de las políticas e inversiones públicas, útiles para el mejoramiento de la calidad ambiental urbana. Organizar, en este sentido, un sistema de indicadores ambientales para la ciudad, se constituye en el propósito mediato de este grupo de investigación: Análisis y Gestión para la Sostenibilidad Ambiental y Territorial -AGESAT-.

\section{Cuadro $\mathrm{N}^{\circ} 5$}

Resultados del ANOVA (post-hoc), con prueba Game-Howell, para evaluar diferencias estadísticas significativas del ICA por pares de uso del suelo urbano*

\begin{tabular}{|l|c|c|c|c|c|c|c|c|}
\hline & $\mathrm{H} 1$ & $\mathrm{H} 2$ & $\mathrm{H} 3$ & $\mathrm{H} 4$ & $\mathrm{CH}$ & $\mathrm{PQ}$ & $\mathrm{HPQ}$ & $\mathrm{H}$ \\
\hline $\mathrm{H} 2$ & $-0,03$ & & & & & & & \\
$\mathrm{H} 3$ & $-0,91$ & $-0,88$ & & & & & & \\
$\mathrm{H} 4$ & $-1,85$ & $-1,82$ & $-0,94$ & & & & & \\
$\mathrm{CH}$ & 0,66 & 0,69 & 1,57 & 2,51 & & & & \\
$\mathrm{PQ}$ & $-2,15$ & $-2,12$ & $-1,24$ & $-0,3$ & $-2,81$ & & & \\
$\mathrm{HPQ}$ & $-1,66$ & $-1,63$ & $-0,75$ & 0,19 & $-2,32$ & 0,49 & & \\
$\mathrm{H}$ & 0,47 & 0,5 & 1,38 & 2,32 & $-0,19$ & 2,62 & 2,13 & \\
$\mathrm{I}$ & 0,04 & 0,06 & 0,95 & 1,89 & $-0,62$ & 2,18 & 1,7 & $-0,43$ \\
\hline
\end{tabular}

* Valores en itálica muestran diferencias estadísticas significativas al 95\%, entre pares de uso del suelo.

Fuente: Elaboración propia. 


\section{Agradecimiento}

Los autores agradecen a la Vicerrectoría de Investigaciones de la Universidad del Valle, Cali, Colombia, la financiación del proyecto de investigación que soporta los resultados aquí presentados. Agradecemos también a la Universidad de Maryland (Global Land Cover Facility server), por proporcionarnos la imagen satelital Landsat.

\section{Referencias bibliográficas}

BUYANTUYEV, A.; WU, J. \& GRIES, C. Estimating vegetation cover in an urban environment base don Landsat ETM+ imagery: A case study in Phoenix, USA. International Journal of Remote Sensing, 2007, vol. 28, № 2, p. 269-291.

CHEN, X.; ZHAO, H.; LI, P. \& YIN, Z. Remote sensing image-based analysis of the relationship between urban heat island and land use/cover changes. Remote Sensing of Environment, 2006, № 104, p. 133-146.

CHOUDHURY, B.; AHMED, N.; IDSO, S.; REGINATO, R. \& DAUGHTRY, C. Relations between evaporation coefficients and vegetation indices studied by made simulation. Remote Sensing of Environment, 1994, No 50, p. 1-17.

CHUVIECO, E. Teledetección ambiental. La observación de la tierra desde el espacio. Barcelona: Editorial Ariel, 2002.

DEPARTAMENTO ADMINISTRATIVO DE PLANEACIÓN (DAP). Cali en cifras 2004. Cali: Alcaldía de Santiago de Cali, 2004.

DOUSSET, B. \& GOURMELON, F. Satellite multi-sensor data analysis of urban surface temperaturas and landcover. ISPRS Journal of Photogrammetry \& Remote Sensing, 2003, No 58, p. 43-54.

ESCOBAR, L. Indicadores sintéticos de calidad ambiental: un modelo general para grandes zonas urbanas. Eure, 2006, vol. XXXII, No 96, p. 73-98.

FUNG, T. \& SIU, W. Environmental quality and its changes, an analysis using NDVI.
International Journal of Remote Sensing, 2000, vol, 21, No 5, p. 1011-1024.

HUETE, A. A soil-adjusted vegetation index (Savi). Remote Sensing of Environment, 1988, No 25, p. 295-309.

HUNT, E.; ROCK, B. \& NOBEL, P. Measurement of leaf relative water content by infrared reflectance. Remote Sensing of Environment, 1987, № 22, p. 429-435.

JAT, M.; GARG, P. \& KHARE, D. Monitoring and modeling of urban sprawl using remote sensing and GIS techniques. International Journal of Applied Earth Observation and Geoinformation, 2008, № 10, p. 26-43.

JOHNSON, D. Métodos multivariados aplicados al análisis de datos. Madrid: International Thomson Editores, 1998.

LANDSAT PROJECT SCIENCE OFFICE. Landsat 7 science data user's handbook, chapter 11 (Data products). Washington: Landsat Project Science Office, 2008. Disponible en Internet: http://landsathandbook.gsfc. nasa.gov/handbook/handbook_htmls/chapter11/chapter11.html

LI, G. \& WENG, Q. Using Landsat ETM+ imagery to measure population density in Indianapolis. Indiana. USA. Photogrammetric Engineering and Remote Sensing. 2005, № 71 , p. 947-958.

LI, F.; JACKSON, T.; KUSTAS, J.; SCHMUGGE, T.; FRENCH, A. \& COSH, $M$. Deriving land surface temperature from Landsat 5 and 7 during SMEX02/SMACEX. Remote Sensing of Environment, 2004, No 92, p. 521-534.

LO, C. \& QUATTROCHI, D. Land-use and land-cover change, urban heat island phenomenon, and health implications: a remote sensing approach. Photogrammetric Engineering \& Remote Sensing, 2003, vol. 69, № 9, p. 1053-1063.

LU, D. \& WENG, Q. Urban classification using full spectral information of Landsat ETM+ imagery in Marion county, Indiana. Photogrammetric Engineering \& Remote Sensing, 2005, vol. 71, No 11, p. 1275-1284. 
MARTINUZZI, S.; GOULD, W. \& RAMOS-GONZÁLEZ, O. Land development, land use, and urban sprawl in Puerto Rico integrating remote sensing and population census data. Landscape and Urban Planning, 2007, No 79, p. 288-297.

MASEK, J.; LINDSAY, F. \& GOWARD, S. Dynamics of urban growth in the Washington DC metropolitan area, 1973-1996, from Landsat observations. International Journal of Remote Sensing, 2000, vol. 21, № 18, p. 3473-3486.

NICHOL, J. \& WONG, M. Modelling urban environmental quality in a tropical city. Landscape and Urban Planning, 2005, № 73, p. 49-58.

PARDO-MERINO, A. y RUIZ-DÍAZ, M.A. SPSS 11. Guía para el análisis de datos. Barcelona: McGraw-Hill Interamericana de España, 2002.

PÉREZ GONZÁLEZ, M.; GARCÍA RODRÍGUEZ, P. y GUERRA ZABALLOS, A. Análisis del clima urbano a partir de imágenes de satélite en el centro peninsular español. Anales de Geografía de la Universidad Complutense, 2003, No 23, p. 187-206.

PRIHODKO, L. \& GOWARD, S. Estimation of air temperature from remotely sensed surface observations. Remote Sensing of Environment, 1997, № 60, p. 335-346.

RODRÍGUEZ, J. y VILLA, M. Distribución espacial de la población, urbanización y ciudades intermedias: hechos en su contexto. En: JORDÁN, R. Y SIMONI, D. (comp.). Ciudades intermedias de América Latina y el Caribe: propuestas para la gestión urbana. Santiago: CEPAL, Dirección General de Cooperación para el Desarrollo, Ministerio de Asuntos Exteriores de Italia, 1998, p. 25-68.

ROGER, A. \& KEARNEY, M. Reducing signature variability in unmixing coastal marsh Thematic Mapper scenes using spectral indices. International Journal of Remote Sensing, 2004, vol. 25, No 12, p. 2317-2335.

ROMERO, H. y VÁSQUEZ, A. Evaluación ambiental del proceso de urbanización de las cuencas del piedemonte andino de Santiago de Chile. Eure, 2005, vol. XXXI, No 94, p. 97-118.

ROSENZWEIG, C.; SOLECKIB, W.; PARSHALLA, L.; CHOPPINGC, M.; POPEC, G. \& GOLDERG, R. Characterizing the urban heat island in current and future climates in New Jersey. Environmental Hazards, 2005, No 6 , p. 51-62.

SANTANA, L. Landsat ETM+ image applications to extract information for environmental planning in a Colombian city. International Journal of Remote Sensing, 2007, vol. 28 , No 19 , p. 4225-4242.

STREUTKER, D. Satellite-measured growth of the urban heat island of Houston, Texas. Remote Sensing of Environment, 2003, № 85, p. 282-289.

TRAN, H.; UCHIHAMA, D.; OCHI, S. \& YASUOKA, Y. Assessment with satellite data of the urban heat island effects in Asian mega cities. International Journal of Applied Earth Observation, 2006, vol. 8, № 1, p. 34-48.

WENG, Q. A remote sensing-GIS evaluation of urban expansion and its impact on surface temperature in the Zhujiang Delta, China. International Journal of Remote Sensing, 2001, vol. 22, No 10, p. 1999-2014.

WENG, Q.; LU, D. \& SCHUBRING, J. Estimation of land surface temperature-vegetation abundance relationship for urban heat island studies. Remote Sensing of Environment, 2004, No 22, p. 1999-2014.

WILSON, J.; CLAY, M.; MARTIN, E.; STUCKEY, D. \& VEDDER-RISCH, K. Evaluating environmental influences of zoning in urban ecosystems with remote sensing. Remote Sensing of Environment, 2003, № 86, p. 303-321.

WONG, N. \& YU, C. Study of green areas and urban heat island in a tropical city. Habitat International, 2005, № 29, p. 547-558.

YUAN, F. \& BAUER, M. Comparison of impervious surface area and normalized difference vegetation index as indicators of surface urban heat island effects in Landsat imagery. Remote Sensing of Environment, 2007, No 106, p. 375-386. 